\title{
O portfólio: um estudo das representações sociais dos licenciandos em ciências biológicas
}

\section{The portfolio: a study of the social representations of the graduating students in biological sciences}

\author{
Ricardo Baratella \\ Universidade de Uberaba
}

\begin{abstract}
Resumo
Esta pesquisa de cunho quanti-qualitativo, pretende identificar e analisar as Representações Sociais dos alunos do curso de Licenciatura em Ciências Biológicas, na modalidade a distância, de uma Universidade de Minas Gerais, no Brasil. Considerando o objeto de estudo desta pesquisa - a construção do Portfólio como instrumento de avaliação formativa - cabe aqui evidenciar o Portfólio como um procedimento de avaliação na Educação a Distância, de organização e reconstrução das aprendizagens, que permite aos alunos participar da formulação e da sistematização dos objetivos propostos, assim como avaliar seu progresso, suas potencialidades e fragilidades.
\end{abstract}

Palavras chave: portfólio; avaliação; representações sociais

\section{Abstract}

This quali-quantitative research intends to identify and analyse the Social Representations of the study at distance's Biological Science students from a University of Minas Gerais, Brazil. Considering the object of the study of this research - the construction of a Portfolio as an instrument of formative evaluation - this study focus on evidencing the Portfolio as a procedure of evaluation in the Education at Distance and the organization and reconstruction of the learning, that permits the students participate of the elaboration and sistematization of the proposed objects, as well as assess their progress, their potentialities and fragilities.

Key words: portfolio, assessment, social representation.

\section{Introdução}

Esta pesquisa, de cunho quanti-qualitativo, pretende identificar e analisar as Representações Sociais dos alunos do curso de Licenciatura em Ciências Biológicas, na modalidade a distância, de uma
Universidade mineira sobre a realização do Portfólio como instrumento de avaliação formativa. Considerando o objeto de estudo desta pesquisa - $a$ construção do Portfólio como instrumento de avaliação formativa -, cabe aqui evidenciar o Portfólio como um procedimento de avaliação na Educação a Distância - de organização e reconstrução das aprendizagens - que permite aos alunos participar da formulação e da sistematização dos objetivos propostos, assim como avaliar seu progresso, suas potencialidades e fragilidades.

O estudo foi realizado por meio de pesquisa bibliográfica e de campo. A pesquisa bibliográfica fundamenta-se em autores da Teoria das Representações Sociais e do Núcleo Central, do Portfólio, da Educação a Distância e da Avaliação formativa.

Participaram da pesquisa de campo 150 alunos do curso de Licenciatura em Ciências Biológicas, na modalidade EAD, dos polos de Barbacena, Belo Horizonte, Governador Valadares, Guanhães, Janaúba, Montes Claros, Teófilo Otoni e Uberaba, que estão cursando as etapas finais da sua formação acadêmica.

A coleta dos dados foi realizada a partir de um questionário. Ele apresenta dois objetivos: o primeiro é identificar o perfil dos sujeitos, uma vez que os dados caracterizadores do perfil apresentam relação com as Representações Sociais; o segundo, identificar se os licenciandos do curso de Ciências Biológicas reconhecem o Portfólio como um instrumento de avaliação formativa.

Quanto aos caminhos metodológicos seguidos, esta investigação, de caráter quanti-qualitativo toma como referencial teórico-metodológico as Representações Sociais, descritas por Moscovici (2003) como expressões do conhecimento reconstruído pelo sujeito a respeito de sua realidade cotidiana.

Essas representações são resultantes da interação social e influenciam o nosso modo de pensar, sentir e agir diante das experiências da vida prática. Por isso, nesta pesquisa destacam-se as atitudes, as percepções, os juízos de valor e as crenças dos alunos do curso de Licenciatura em Ciências Biológicas, no que se refere à construção do Portfólio na modalidade a distância. Nesse sentido, algumas questões norteiam esse estudo: quais os princípios de uma avaliação formativa? $\mathrm{O}$ que caracteriza o Portfólio como avaliação formativa. A Representação Social que se 
apresenta sobre o Portfólio, as orientações para sua construção, à forma como ele é construído denotam que o seu uso tem sido utilizado adequadamente, ou seja, de acordo com propostas de avaliação formativa?

\section{A avaliação formativa}

A terminologia avaliação formativa, somente se tornou conhecida com o auxílio de Scriven (1967), "filósofo científico que contribuiu vastamente para o desenvolvimento da profissão avaliativa". (VIEIRA; SOUSA, 2006, p. 42).

$\mathrm{Na}$ avaliação formativa, embora conduzida pelo docente, os alunos exercem um papel dinâmico e central. Atua-se, nesse particular, ativamente, sobre a aprendizagem dos alunos e identifica-se o seu progresso e esforço individual, bem como outros aspectos que não encontra especificado no currículo. Assim eles progredirão se compreenderem suas potencialidades, fragilidades e se souberem como se relacionar com elas. Nesse sentido, a avaliação formativa se distancia da avaliação tradicional, excludente, autoritária e unilateral.

Harlen e James (1997, p. 366) apontam as seguintes características da avaliação formativa: é conduzida pelo professor (esta é a principal); destina-se a promover a aprendizagem; leva em conta o progresso individual, o esforço nele colocado e outros aspectos não especificados no currículo; em outras palavras, não é inteiramente baseada em critérios; são considerados vários momentos e situações em que certas capacidades e ideias são usadas, as quais poderiam classificar-se como "erros" na avaliação somativa, mas que, na formativa, fornecem informações diagnósticas; os alunos exercem papel central, devendo atuar ativamente em sua própria aprendizagem.

A essência da avaliação formativa recai sobre duas ações. A primeira é a percepção dos estudantes sobre a lacuna entre o objetivo a atingir e a situação em que sua aprendizagem se encontra em relação a ele. A segunda é o que eles fazem para eliminar a lacuna e atingir o objetivo. Em relação à primeira ação, a atividade fundamental para gerar a informação pode ser a autoavaliação ou a ajuda de outra pessoa, como o professor, que identifica e interpreta a lacuna e torna o aluno ciente de sua necessidade. (VILLAS BOAS, 2011, p.25).

Na Educação Superior, é imprescindível que o professor convide os estudantes a se tornarem corresponsáveis pelo processo avaliativo, visto que eles estão em formação e necessitam de refletir sobre os critérios avaliativos da perspectiva de vivenciar as ideias que compõem a avaliação formativa, os seus aspectos éticos e técnicos, além de ter a oportunidade de construí-los e validá-los. Afinal, estamos formando profissionais nas Licenciaturas, que poderão se envolver com a coordenação da avaliação em seus campos de trabalho. (BATISTA, 2011).

A prática de educadores com a avaliação formativa já vem sendo construída há alguns anos e, pelo seu caráter emancipatório, autônomo, reflexivo e dialógico, assim como pelo seu comprometimento com as aprendizagens dos estudantes, contribui fortemente para o trabalho do professor pesquisador.

Uma avaliação formativa é a que utiliza todas as informações e os registros disponíveis sobre o estudante, para assegurar e promover a sua aprendizagem. A interação entre docente e estudante, durante todo o curso, é um processo muito rico em conhecimentos, oferecendo oportunidades para que se selecionem várias informações e realizem a coleta de dados. Cabe ao professor estar atento para identificálos, analisá-los, registrá-los e usá-los em benefício da construção da aprendizagem. Portanto, a utilização exclusiva de avaliações tradicionais para decidir a trajetória de estudos do aluno deixa de considerar as diferentes linguagens, estilos e manifestações da aprendizagem.

\section{Portfólios: instrumentos de avaliação formativa}

Em educação, o Portfólio apresenta várias possibilidades; uma delas é a sua construção pelo aluno. Nesse caso, é uma coleção de suas produções, as quais apresentam as evidências de sua aprendizagem. É organizado por ele próprio para que, junto com o professor, possam acompanhar o seu progresso. (VILLAS BOAS, 2001, p. 207).

As construções de Portfólios nos oferecem importantes elementos para análise. Em primeiro lugar - o seu uso pode ser benéfico a uma multiplicidade de diferentes tipos de estudantes: o extrovertido, o tímido, o mais e o menos dedicado aos seus estudos e aos registros das aprendizagens, o que se sente à vontade e gosta de trabalhar coletivamente e o que não gosta, o que gosta de pesquisar, de ler e de escrever e até o que não gosta, assim como pode ou não apresentar suas produções usando outras linguagens, diferentes suportes metodológicos. A construção do Portfólio permite ao aluno acompanhar o desenvolvimento de suas aprendizagens, de modo a conhecer suas fragilidades, suas potencialidades e os aspectos que precisam ser melhorados ou modificados em suas produções textuais. O esforço do estudante é analisado, interpretado, valorizado e reconhecido. As notas, os conceitos e as menções, se existirem, passam a ocupar um lugar secundário nesse processo avaliativo.

Em segundo lugar - os estudantes declaram sua autonomia, seus sentimentos, suas percepções e sua identidade, isto é, mostram-se como sujeitos dispostos a aprender e a reorganizar suas aprendizagens. Sua história de vida, suas vivências escolares ou não e suas experiências são conhecidas, registradas, valorizadas e partilhadas com seus pares.

Em terceiro lugar - as atividades e as produções que irão compor o Portfólio levam em conta as experiências que são vividas pelos estudantes fora da escola, proporcionando a ampliação e a retificação dos saberes, permitindo a formação de sujeitos reflexivos na construção de sua própria aprendizagem.

Em quarto lugar - o estudante percebe a sua autonomia processualmente; portanto, cabe-lhe assumir responsabilidades por sua execução na construção do Portfólio. Ele não está produzindo algo para agradar a outras pessoas, mas está oferecendo oportunidades de 
reorganizar suas aprendizagens em seu próprio benefício, assim o trabalho escolar e o processo avaliativo passam a ser formativos e prazerosos.

Em quinto lugar - a construção do Portfólio motiva os estudantes a buscarem diferentes linguagens, formas diferentes de aprender e de correlacionar informações, conceitos e experiências vivenciadas no cotidiano. Nesse contexto, suas produções e suas reflexões revelam suas capacidades e suas potencialidades, permitindo ao educando a autoavaliação, o autoconhecimento, a criticidade e a criatividade. Amplia-se, assim, a concepção de avaliação, que deixa de ter a função somente de verificar a aprendizagem para possibilitar ao estudante incorporar o que aprendeu, preparando-o para defender suas posições em relação às situações-problemas que permeiam a sua formação acerca de seu próprio desenvolvimento.

Barton e Collins (1997, p.2) apontam sete características essenciais para o desenvolvimento de Portfólios. Em primeiro lugar, eles incluem múltiplos recursos, porque permitem avaliar variedade de evidências. Em segundo lugar, são autênticos, porque as produções dos alunos se articulam ao trabalho em desenvolvimento. Em terceiro lugar, o Portfólio é uma forma dinâmica de avaliação pelo fato de constatar o desenvolvimento e as mudanças dos alunos ao longo do tempo. A quarta característica é a explicitação dos seus propósitos. Antes de a construção do Portfólio ter início, os alunos conhecem o que se espera deles. Esta conduz à quinta característica - integração. Isso significa que as evidências de aprendizagem selecionadas estabelecem correspondência entre as atividades escolares e as experiências de vida. O pertencimento do trabalho ao aluno é a sexta característica. Nesse sentido, cada Portfólio é uma criação única, porque o próprio aluno escolhe as produções que incluirá e insere reflexões sobre o desenvolvimento de sua aprendizagem. A sétima característica é a natureza multiproposital do Portfólio. O professor pode avaliar o trabalho pedagógico que coordena, usando as mesmas evidências para avaliar a aprendizagem dos alunos.

O Portfólio é um procedimento de avaliação na educação superior em que discentes e docentes atuam em parceria, em conjunto. Por isso, é uma forma autêntica de avaliação formativa, que oportuniza aos estudantes desenvolver habilidades, que lhes serão úteis e significativas por toda a vida. A elaboração do Portfólio também é realizada por meio de reflexões, outro princípio norteador desse trabalho de aprendizagens. Por intermédio das reflexões, o aluno decide o que e como registrar, o que incluir, ao mesmo tempo, analisa suas atividades, suas produções, tendo a oportunidade de reorganizá-las e refazê-las sempre que quiser e for necessário.

A prática da avaliação formativa, por meio do Portfólio, baseia-se na ideia de que avaliação é autoconhecimento e investigação: de como os estudantes aprendem, o que aprendem, de que maneira produzem ou constroem suas aprendizagens, o que produzem, como refletem, o que refletem, suas potencialidades e suas fragilidades, sua compreensão do mundo.

Uma avaliação formativa deve apoiar, corrigir, harmonizar, inventariar, orientar, reforçar e tranquilizar os acadêmicos durante a seleção e a formulação de questões e materiais que encorajem a construção e a continuidade do trabalho pedagógico.

O Portfólio não é uma avaliação classificatória nem punitiva; por meio dele, analisa-se o progresso do aluno. Valorizam-se, nesse âmbito, todas as suas produções; analisam-se as últimas, comparando-as com as primeiras, de modo a perceber o avanço obtido. Isso requer que a construção do Portfólio se baseie em propósitos de cuja formulação o aluno participe, para que se desenvolva o sentido de "pertencimento". Desse modo, o Portfólio extrapola sua função avaliativa e passa a ser o eixo organizador do trabalho pedagógico, porque este assume outro significado: o aluno é corresponsável por sua organização. (VILLAS BOAS, 2004).

Hernández (1998), ao afirmar que um Portfólio é um "continente de diferentes classes de documentos”, proporciona, no campo da educação, evidências do conhecimento e das aprendizagens construídas pelos alunos, de maneira permanente, processual e multidimensional; sem dúvida, o Portfólio não é algo estático e abstrato, é um processo avaliativo formativo, que ocorre ao longo de toda a vida e se estende em múltiplos espaços e tempos. Sá-Chaves (1998, p.140) refere-se ao Portfólio como uma “metodologia”, cuja tônica é possibilitar o sucesso do estudante. Essa autora salienta que o trabalho é feito de "forma partilhada, sempre aberta ao seu próprio fluir”.

A partir das análises dos significados, das justificativas das palavras evocadas e das experiências vivenciadas pelos licenciandos concluintes do curso de Licenciatura em Ciências Biológicas-EAD, ancorei os objetivos específicos desta pesquisa, identificando duas categorias de alunos, em relação à construção do Portfólio como instrumento de avaliação formativa nessa Universidade mineira: (i) GRUPO $\boldsymbol{\alpha}$ - os que consideram o Portfólio como um instrumento de avaliação difícil de ser construído e desnecessário como processo avaliativo na graduação e o (ii) GRUPO $\boldsymbol{\beta}$ - os que consideram o Portfólio como um instrumento de avaliação formativo, que produz resultados satisfatórios. Essa identificação, realizada com base nas análises dos resultados, possibilitou compreender os significados que se organizam e definem, para cada um desses grupos de alunos, o sentido de Portfólio, permitindo, assim, analisar as Representações Sociais construídas por eles.

Assim, pode-se alegar que, no GRUPO $\boldsymbol{\alpha}$, com uma representatividade de 12,67\%, 19 sujeitos não acreditam nessa forma de avaliar e não aprovam o uso do Portfólio. Alguns acadêmicos afirmaram que o uso do Portfólio é uma "enganação", outros elucidaram que é uma produção que "não avalia os alunos", é uma "mentira" e está mais próximo do "faz de conta do que aprendi", assim como revelaram que é "difícil" construí-lo e que também "demanda muito tempo" para fazê-lo. 
O conteúdo das respostas foi analisado e ancorei alguns aspectos que constatei ser mais representativos no GRUPO $\boldsymbol{\alpha}$ : os alunos têm demonstrado que necessitam de acompanhamento constante nesse trabalho avaliativo, por parte dos professores-tutores. Algumas dificuldades, percepções ou sentimentos foram elencados ao analisar os resultados desta pesquisa; como, por exemplo: falta de hábito por parte dos estudantes, de pesquisarem, de interpretarem dados, de correlacionarem informações, de escreverem e analisarem o que produzem, de refletirem sobre suas aprendizagens e escolherem suas melhores produções para compor o Portfólio. Em algumas situações, embora mais raras, não constroem o Portfólio ao longo do semestre ou constroem o material de forma quase mecânica e repetitiva, sem contextualizar fatos e informações e há, em alguns casos, a argumentação da falta de tempo, já que muitos estudantes trabalham na zona rural ou em outros municípios, distantes dos polos de apoio presencial. Existem também aqueles licenciandos que dificilmente conseguem acessar a internet no município em que moram ou possuem dificuldades em trabalhar com as ferramentas do ambiente virtual ou ainda não sabem pesquisar e "navegar” na internet.

Para não reprovar diretamente o uso do Portfólio como instrumento de avaliação formativa na $E A D$, alguns licenciandos utilizaram argumentos desviantes, "meias verdades", que realmente não justificam a negação desse processo avaliativo, mas atuam no sentido de construir uma visão de que esse instrumento é cansativo, complicado. extenso,mal avaliado e que possui muitas regras. Nessa Universidade mineira, cada turma tem um semestre para construir o Portfólio na etapa e as orientações ocorrem nos encontros acadêmicos, nos plantões que são previamente agendados nos polos de apoio presencial, assim como estão disponibilizadas no AVA e na Biblioteca do curso. Além disso, durante a etapa (06 meses), o aluno tem um professor-tutor para auxiliá-lo no acompanhamento, orientá-lo, estimulá-lo e que corrige as suas produções, processualmente.

No GRUPO $\boldsymbol{\beta}$, a ancoragem desses resultados mostra-se bastante expressiva, indicando diferentes Representações Sociais dos alunos sobre a construção do Portfólio. Dos 150 estudantes que participaram da pesquisa, 131 alunos, ou seja, 87,33\% dos sujeitos revelaram que a construção do Portfólio é um instrumento de avaliação formativa na EAD e o consideram uma forma de minimizar as avaliações unilaterais, excludentes e punitivas no Ensino superior. A apreciação das Representações Sociais construídas por esses sujeitos corroboraram em minha hipótese de pesquisa e os resultados mostraram que algumas constâncias apareceram na análise mais acurada das entrevistas. Constatei também que os licenciandos em Ciências Biológicas compartilham uma representação comum, cujo núcleo central é composto pelos campos semânticos: aprendizagem; conhecimento; pesquisa e reflexões.

Essas palavras configuram-se como elementos do núcleo central, caracterizam a parte mais consensual e estável da representação, foram as palavras evocadas com maior frequência pelos alunos do curso de Licenciatura em Ciências Biológicas e dão um sentido maior ao objeto de estudo: a construção do Portfólio como instrumento de avaliação formativa.

Nesse contexto, relaciono algumas argumentações dos discentes com as palavras que constituem o núcleo central desta pesquisa, e averiguei que o emprego do Portfólio, como instrumento avaliativo, no curso de Ciências Biológicas, mostra-nos que a construção do Portfólio pode ser um instrumento de avaliação formativa: “o Portfólio é um instrumento avaliativo, de registro da aprendizagem ao longo de uma etapa" ou para "construirmos o Portfólio é preciso desenvolver o hábito da pesquisa ou até mesmo os alunos revelaram que o Portfólio é um instrumento de avaliação, de registro das produções, das reflexões, das aprendizagens significativas e do conhecimento adquirido em uma etapa.

A partir das argumentações e de minhas análises, verifiquei que o Portfólio pode ser considerado um instrumento de avaliação formativa no curso de Ciências Biológicas, em que os licenciandos revelam seus processos de ensino e aprendizagem, seu modo de pensar e as maneiras de organizar e gerar a infinitude de variáveis presentes em cada ato pedagógico.

Examinei também que o Portfólio trazia as seguintes contribuições para os alunos: visão ampliada de avaliação formativa; vivências e experiências de uma avaliação processual; o constante "refletir" sobre a prática pedagógica; auto-organização de suas ideias e registros das aprendizagens significativas; compreensão do trabalho pedagógico e reflexões sobre temas do curso; a prática da autoavaliação; desenvolvimento da capacidade de pesquisa e leitura de materiais diversos; reflexão e análise dos aspectos que precisavam ser melhorados; troca de experiências e utilização de diferentes linguagens; desenvolvimento da criticidade, sem medo de expressar-se; aprimoramento formativo e reflexivo que o Portfólio desencadeia; construção da autonomia intelectual e reorganização das aprendizagens.

Assim, podemos edificar representações, acerca do Portfólio, como um instrumento avaliativo, construído pelos alunos e que permite não só avaliar, mas também refletir, demonstrar, criticar, comparar, reorganizar suas aprendizagens, trabalhar de forma colaborativa com os professores-tutores, articular e solucionar problemas de modo a criar condições para um constante crescimento pessoal e profissional dos estudantes.

\section{Considerações finais}

A Educação a Distância, nessa Universidade mineira, consolida-se em uma prática educativa de interação pedagógica, cujos objetivos, conteúdos e resultados obtidos se identificam com aqueles que caracterizam a educação como projeto e processo humano histórico e politicamente definido na cultura das diferentes sociedades. 
O Portfólio apresenta aspectos de sociabilidade, de interações entre seus pares e de ordem emocional em suas produções. Portanto, pode deixar de ser seletivo, sendo um instrumento avaliativo que permite um novo sentido no contexto educativo, na Educação a Distância.

Construir e fazer Portfólio e refletir sobre as suas aprendizagens é estar ciente de ser autônomo e responsável pela construção do próprio conhecimento e, nessa dinâmica, aprender que esse processo será ferramenta de trabalho de um futuro educador: um profissional capaz de construir estratégias necessárias para cada situação, sendo participativo e criativo para buscar novas linhas de ação.

Podemos verificar que as representações construídas por meio do Portfólio como instrumento de avaliação no curso de Licenciatura em Ciências Biológicas se comprometem com a aprendizagem de cada estudante e deixam de ser classificatórias e unilaterais, possibilitando que as produções e reflexões dos alunos sejam avaliadas por eles próprios e pelo professor. Mas, para que se chegue a um trabalho reflexivo, processual e criterioso, há necessidade de atenção individual a esses estudantes e orientação sobre os objetivos dessa avaliação e como podem desenvolver o Portfólio e registrar as suas aprendizagens durante a etapa.

Concluindo, pode-se afirmar que a construção do Portfólio, no curso de Ciências Biológicas da Universidade mineira, apresenta elementos que o caracterizam como instrumento de avaliação formativa. Porém, sugiro à instituição estudos mais sistematizados sobre a construção do Portfólio, visando a expandir o repertório de variáveis e conhecimentos sobre esse sistema de avaliação formativo, já que, ao mesmo tempo, esse processo cria representações que irão dificultar sua prática pelos próprios alunos.

Entendo que empreender uma pesquisa, procurando identificar quais são as Representações Sociais dos licenciandos em Ciências Biológicas, na modalidade a distância sobre a construção do Portfólio como instrumento de avaliação formativa, pode traduzir-se em contribuições relevantes para cursos de formação de professores e instituições que utilizam ou têm intenção de utilizar o Portfólio como instrumento de avaliação formativa.

\section{Referências bibliográficas}

BARTON, J.; COLLINS, A. Portfolio assessment: a handbook for educators. Nova York: Dale Seymour Publications, 1997.

BATISTA, C. O. O processo comunicacional da avaliação nas práticas de professores universitários. In: Avaliação formativa: práticas inovadoras / Benigna Maria de Freitas Villas Boas (Org.). Campinas: Papirus (Coleção Magistério: Formação e Trabalho Pedagógico), 2011.

HARLEN, W.; JAMES, M. Assessment and learning: Differences and relationships between formative and summative assessment. Assessment in Education: principles, policy e practice, Reino Unido, v.4 , n.3, p. 365-379, 1997.

HERNÁNDEZ, F. Transgressão e mudança na educação: os projetos de trabalho. Porto Alegre: Artmed, 1998.

MOSCOVICI, S. Representações sociais: investigações em psicologia social. Petrópolis: Vozes, 2003.

SÁ-CHAVES, I. Porta-fólios. No fluir das concepções, das metodologias e dos instrumentos. In: ALMEIDA, L.S. ; TAVARES, J. (Orgs.). Conhecer, aprender, avaliar. Porto: Porto editora, 1998.

SCRIVEN, M. The methodology of evaluation. In: TYLLER, R.; GAGNE, R. e SCRIVEN, M. Perspectives on curriculum evaluation. (Aera Monography Series on Curriculum Evaluation 1). Chicago: Rand McNally and Company, 1967.

VIANNA, H. M. Avaliação educacional e o avaliador. Tese (Doutorado em Psicologia da Educação). Pontifícia Universidade Católica de São Paulo, 1997.

VIEIRA, V. M. O; SOUSA, C. P. Representações sociais e avaliação educacional: o que revela 0 Portfólio. Tese (Doutorado em Psicologia da Educação) - Pontifícia Universidade Católica de São Paulo, 2006.

VILLAS BOAS, B. M. de F. Compreendendo a avaliação formativa. In: Avaliação formativa: práticas inovadoras / Benigna Maria de Freitas Villas Boas (Org.). Campinas: Papirus (Coleção Magistério: Formação e Trabalho Pedagógico), 2011.

Portfólio, avaliação e trabalho pedagógico. Campinas: Papirus, 2004.

Compreendendo a avaliação formativa. In:

Avaliação formativa: práticas inovadoras / Benigna Maria de Freitas Villas Boas. (Org.). Campinas: Papirus (Coleção Magistério: Formação e Trabalho Pedagógico), 2001. 